\title{
Spontaneous grafting of nitrophenyl groups on amorphous carbon thin films: A structure-reactivity investigation
}

\begin{tabular}{|r|l|}
\hline Journal: & Chemistry of Materials \\
\hline Manuscript ID: & cm-2011-030262.R1 \\
\hline Manuscript Type: & Article \\
\hline Complete List of Authors: & Cullen, Ronan; Trinity College Dublin, School of Chemistry \\
& $\begin{array}{l}\text { Jayasundara, Dilushan; Trinity College Dublin, School of Chemistry } \\
\text { Soldi, Laura; Trinity College Dublin, School of Chemistry } \\
\text { Cheng, Jayce; Trinity College Dublin, School of Chemistry } \\
\text { Dufaure, Gaelle; Trinity College Dublin, School of Chemistry } \\
\text { Colavita, Paula; Trinity College Dublin, Chemistry }\end{array}$ \\
\hline &
\end{tabular}

\section{SCHOLARONE \\ Manuscripts}




\section{Spontaneous grafting of nitrophenyl groups on}

\section{amorphous carbon thin films: A structure-reactivity investigation}

Ronan J. Cullen, ${ }^{a}$ Dilushan R. Jayasundara, ${ }^{a}$ Laura Soldi, ${ }^{a}$ Jayce J. Cheng, ${ }^{a}$ Gaelle Dufaure, ${ }^{a}$ and Paula E. Colavita., *

a - School of Chemistry, University of Dublin Trinity College, College Green, Dublin 2, Ireland.

\footnotetext{
*Corresponding author. E-mail: colavitp@tcd.ie.
} 


\begin{abstract}
\end{abstract}
Amorphous carbon materials find numerous applications in diverse areas ranging from implantable biodevices to electronics and catalysis. The spontaneous grafting of aryldiazonium salts is an important strategy for the modification of these materials and it is widely used in order to display a range of functionalities or to provide anchoring groups for further functionalization. We have investigated the spontaneous attachment of 4-nitrobenzenediazonium salts from aqueous solutions onto amorphous carbon materials that differ in their $\mathrm{sp}^{2}$ content with the aim of understanding to what extent bulk composition affects rates and yields of aryldiazonium adsorption at the carbon/solution interface. Amorphous carbons were deposited in the form of thin films via reactive magnetron sputtering, and were characterized using a combination of Raman, infrared, UV-Vis and X-ray Photoelectron Spectroscopy in order to determine their $\mathrm{sp}^{2}$ content. Attenuated Total Internal Reflection Fourier Transform Infrared spectroscopy (ATR-FTIR) was used to monitor in situ and in real time the aryldiazonium adsorption process at the carbon/solution interface. These measurements demonstrate that rates and yields of adsorption for the same aryldiazonium salt increase non-linearly vs. $\mathrm{sp}^{2}$ concentration. Studies of aryldiazonium salt grafting as a function of time carried out ex situ via cyclic voltammetry showed that the amorphous carbon film with highest $\mathrm{sp}^{2}$ content displays significantly lower grafting yields than glassy carbon, a material with $100 \% \mathrm{sp}^{2}$ content. Intercalation experiments using 4-nitrobenzylamine suggest that the difference in relative density of graphitic edge planes exposed at the carbon surface is in excellent agreement with the observed relative grafting yields. We discuss the implications of these results for the development of structure/reactivity relationships that can be leveraged for understanding the surface chemistry of disordered carbon materials.

Keywords: diazonium, nitrophenyl, p-nitrobenzene diazonium, amorphous carbon, electron transfer, ATR-FTIR. 


\section{Introduction}

Carbon materials and coatings are widely used for a vast range of applications, from charge storage to catalyst supports, structural components, and medical implantable devices. Many of these applications rely on the ability to control the interfacial properties of carbon, especially surface chemistry and reactivity. For instance, O-containing surface groups are known to play an essential role in electrocatalysis at carbon electrodes, while N-containing groups are known to be responsible for the catalytic activity of carbons in oxidation reactions. ${ }^{1}$ Surface groups on carbon scaffolds are also used as anchoring points for biomolecules or nanomaterials in order to achieve complex functionality. ${ }^{2-4}$ Finally, adsorbed or chemisorbed molecules with electron accepting/donating groups can be used to modulate the electronic properties of carbons. ${ }^{5-10}$ The wide range of functions that can be fine tuned via surface chemistry has therefore generated great interest, not only in developing new functionalization strategies, but also in achieving a fundamental understanding of what factors control surface reactivity at carbon substrates.

The development of structure-reactivity relationships between physical and chemical properties of carbon and their surface reactivity can lead to significant progress towards the design of functional carbon based materials and devices. For example, Strano and co-workers have developed structurereactivity relationships for carbon nanotubes by investigating the rate of their surface reaction with aryldiazonium salts. They have shown that, compared to semiconducting tubes, metallic nanotubes display faster reaction rates with substituted benzenediazonium salts and they have developed a kinetic model to explain the relationship between nanotube electronic properties and reaction rates. ${ }^{11-13}$ Researchers have leveraged this selective surface reactivity for preparative separation of nanotubes ${ }^{14,15}$ and for improving the performance of nanotube-based electronic devices. ${ }^{16,17}$ More recently, the rate of aryldiazonium reactions at graphene single and multilayers has been investigated and observed rates have been rationalized in terms of the electronic properties of graphene nanostructures. ${ }^{18-20}$

Amorphous carbons in the form of micro- and nanoparticles or thin film materials are of great technological importance and are currently used in a number of applications, ranging from biomedical 
devices to sensors and electronics; however, very little is known about the interplay between their bulk properties and their surface chemistry. These materials present an interesting surface chemistry problem because their bulk structure is heterogeneous, typically described as a mixture of $\mathrm{sp}^{2}$ clusters embedded in an $\mathrm{sp}^{3}$ matrix, with electronic properties ranging from semimetallic to semiconducting. ${ }^{21-23}$ Although the surface chemistry of disordered carbons would be expected to range from graphite-like to diamondor polymer-like when varying their composition, it is not yet clear to what extent surface reactions are affected by composition heterogeneity. Pronounced effects of bulk composition on surface reactions were observed by Hamers and co-workers for the photochemical grafting of alkenes, ${ }^{24-26}$ thus suggesting that carbon composition/structure can indeed affect surface reactivity. Similarly, Downard and coworkers showed that glassy carbon and pyrolyzed films displayed marked differences in reactivity towards aryldiazonium grafting. ${ }^{27}$ These reports therefore suggest that carbon structure affects reaction rates at their surface and that, likewise, it should be possible to use surface reactions as a tool to characterize the surface of disordered carbons, as previously achieved for nanomaterials such as graphene and nanotubes.

In this work we investigated the rate of the spontaneous reaction of aryldiazonium salts on amorphous carbons of varying $\mathrm{sp}^{2} / \mathrm{sp}^{3}$ composition. This reaction is one of the most popular approaches to the covalent functionalization of carbons ${ }^{28}$ and has been shown to result in carbon/aryl layers on ordered carbon materials such as graphite, ${ }^{29}$ diamond, ${ }^{30}$ nanotubes ${ }^{11,31}$ and graphene, ${ }^{20,32}$ as well as on disordered carbons. ${ }^{33-35}$ We have used a combination of electrochemical and spectroscopic techniques in order to correlate surface composition to reactivity in disordered carbons of varying $\mathrm{sp}^{2} / \mathrm{sp}^{3}$ composition. Also, we report the first in situ, real time studies of the grafting kinetics of aryldiazonium at the carbon/solution interface using non-conductive carbon substrates. To our knowledge, this is the first study that directly correlates reaction rates of aryldiazonium grafting to surface composition and $\mathrm{sp}^{2} / \mathrm{sp}^{3}$ content in disordered carbons. Our results show that $\mathrm{sp}^{2}$ content at the carbon surface positively correlates with aryldiazonium reaction rates, thus suggesting a potentially new approach to the characterization of the surface chemistry of these materials. 


\section{Experimental Section}

Chemicals and Materials. Dichloromethane (Fisher, analytical grade), acetonitrile (Sigma, reagent grade), acetone (Sigma, reagent grade), and methanol (Sigma-Aldrich, semiconductor grade) were used without further purification. Hexaammineruthenium(III) chloride (Aldrich), potassium ferricyanide (Aldrich) potassium chloride (Sigma-Aldrich), sulfuric acid (Sigma-Aldrich, concentrated), and hydrogen peroxide (Sigma-Aldrich, 30\%) were used as received. Spontaneous grafting of carbon substrates was performed with 4-nitrobenzenediazonium tetrafluoroborate (pNBD, Aldrich). 4nitrobenzylamine (4-NBA) was prepared from 4-nitrobenzylamine hydrochloride salt (Aldrich) according to published protocols. ${ }^{36}$

Deposition of Amorphous Carbon Films. Amorphous carbon films with thickness ranging between 80 and $100 \mathrm{~nm}$ were prepared via DC-magnetron sputtering (Torr International, Inc.) at a base pressure $\leq 2 \times 10^{-6}$ mbar and a deposition pressure of $7 \times 10^{-3}$ mbar. All depositions were performed with the substrate at $100{ }^{\circ} \mathrm{C}$. Three distinct films were prepared by varying the $\mathrm{H}_{2} / \mathrm{Ar}$ gas content while sputtering. One type of film was sputtered in an Ar atmosphere and shall be referred to as a-C from here on in. The two remaining films were hydrogen doped via $\mathrm{H}_{2}$ introduction during deposition at concentrations of 1.4 and $10 \%$ and shall respectively be referred to as a-C:H1 and a-C:H2.

Sputter-coating was performed on quartz (UQG Optics) slides for UV-Vis measurements, on silicon wafers for infrared and Raman spectroscopy, and on stainless steel substrates for electrochemical characterization. All substrates, with the exception of stainless steel, were cleaned prior to deposition using piranha solution; this solution was made by mixing $\mathrm{H}_{2} \mathrm{SO}_{4}$ and $\mathrm{H}_{2} \mathrm{O}_{2}$ in a 3:1 ratio (Caution: piranha solutions react violently with many organic materials and should be handled with extreme care). Stainless steel was cleaned via sonication in deionized water, acetone and methanol.

Surface modification of carbon substrates. pNBD layers were deposited from $6 \times 10^{-4} \mathrm{M}$ aqueous solutions of pNBD over times ranging between $5 \mathrm{~s}$ and $3 \mathrm{~h}$. Prior to functionalisation, GC substrates (SPI-Glas $^{\mathrm{TM}} 11$ Grade) were polished with $0.3 \mu \mathrm{m}$ alumina slurry (Buehler), rinsed with water, 
immersed $20 \mathrm{~s}$ in piranha to remove the polishing debris layer, ${ }^{37}$ rinsed with abundant water and finally annealed under $\mathrm{N}_{2}$ for $1 \mathrm{~h}$ at $500{ }^{\circ} \mathrm{C}$. Amorphous carbon films were used as deposited. After pNBD functionalisation samples were washed and sonicated in dichloromethane and acetonitrile in order to remove any physisorbed material prior to ex situ characterization. 4-NBA intercalation experiments were carried out, according to published protocols, ${ }^{36}$ by immersing the carbon substrates in $6 \times 10^{-4} \mathrm{M} 4$ NBA solutions in acetonitrile for $2 \mathrm{~h}$ under stirring (intercalation experiments as a function of time showed that 4-NBA surface coverage reaches a steady state value after $1 \mathrm{~h}$ of immersion for both GC and a-C substrates). Samples were rinsed with abundant acetonitrile and dried prior to ex situ characterization via cyclic voltammetry.

Characterization of Amorphous Carbon Films. UV-Vis transmission measurements of amorphous carbon films were obtained from samples deposited on quartz substrates over the wavelength range 300$890 \mathrm{~nm}$ at $1 \mathrm{~nm}$ resolution (Shimadzu UV-2401 PC). Atomic Force Microscopy (AFM, NT-MDT) measurements were carried out in tapping mode with a frequency of $0.5 \mathrm{~Hz}$ and 512 scan lines; RMS roughness values were calculated over $10 \times 10 \mu \mathrm{m}^{2}$ boxes. Raman spectra were collected on a microRaman system (Renishaw 1000) equipped with a CCD camera and a Leica microscope. The $514 \mathrm{~nm}$ line of an $\mathrm{Ar}^{+}$laser was used as the excitation source. A grating with 1800 lines/mm was used for all measurements, providing a spectral resolution of $\sim 1 \mathrm{~cm}^{-1}$. Spectra were collected in extended mode with $20 \mathrm{~s}$ exposure time, 5 accumulations, and a laser power of $1 \mathrm{~mW}$ to avoid laser burning of the carbon films.

FTIR spectra were collected on a Bruker Tensor 27 FTIR Spectrometer at $4 \mathrm{~cm}^{-1}$ resolution. All three types of amorphous carbon films were deposited on undoped silicon substrates in order to obtain their transmission spectra, or on Si trapezoids in order to perform ATR-FTIR measurements (see below).

X-ray photoelectron spectroscopy (XPS) characterization was performed on an ultra-high vacuum system (Omicron) at $1 \times 10^{-10}$ mbar base pressure, equipped with a monochromatized $\mathrm{Al} \mathrm{K}_{\alpha}$ source (1486.6 eV) and a multichannel array detector. Spectra were recorded with an analyzer resolution of $0.5 \mathrm{eV}$ at $45^{\circ}$ take-off angle. Peaks were fitted to Voigt functions after Shirley background 
correction $^{38,39}$ using commercial software (Igor Pro); atomic ratios were obtained from area ratios using sensitivity factors $(\mathrm{C}=0.296 ; \mathrm{O}=0.711)$.

Cyclic voltammetry (CV) was performed with a three-electrode setup (CHI660C potentiostat) using Pt wire and $\mathrm{Ag} / \mathrm{AgCl}$ as counter and reference electrodes (IJ Cambria), respectively. A home-built Teflon cell was used, in which a Viton o-ring was pressed against a-C or glassy carbon (GC) working electrodes, thus defining a constant electrode area. For electrochemical measurements, sputtered carbon working electrodes were deposited on stainless steel foils. Measurements were performed at room temperature in Ar purged solutions containing $0.001 \mathrm{M} \mathrm{K}_{3} \mathrm{Fe}(\mathrm{CN})_{6}$ or $\left[\mathrm{Ru}\left(\mathrm{NH}_{3}\right)_{6}\right] \mathrm{Cl}_{3}$, and $0.1 \mathrm{M} \mathrm{KCl}$ or $\mathrm{H}_{2} \mathrm{SO}_{4}$ as supporting electrolytes, depending on the specific experiment.

Real-time characterization of reactions at the carbon/aqueous interface. The in situ monitoring of the spontaneous grafting of pNBD onto a-C films was performed using a custom-built ATR-FTIR setup. The internal reflection element was made from $1245 \mu \mathrm{m}$ thick, double side polished, undoped silicon wafers (Virginia Semiconductors, resistivity $>100 \Omega-\mathrm{cm}$ ). A rectangular piece approximately $2.5 \times 1 \mathrm{~cm}^{2}$ in size was cleaved and polished at $45^{\circ}$ to fabricate trapezoids for ATR experiments. The trapezoid was sputter coated on its longest face with $\mathrm{a}-\mathrm{C}, \mathrm{a}-\mathrm{C}: \mathrm{H} 1$ or $\mathrm{a}-\mathrm{C}: \mathrm{H} 2$ films depending on the experiment. A PDMS gasket was used to seal the carbon side of the trapezoid forming a liquid cell. Background spectra were collected via injection of deionized water; afterwards, a degassed $1 \times 10^{-4} \mathrm{M}$ pNBD aqueous solution was injected into the cell. Spectra were collected at regular time intervals after injection; a minimum of 50 scans at $4 \mathrm{~cm}^{-1}$ resolution were averaged for each time point over the course of $3 \mathrm{~h}$. Upon completion of the grafting experiment a $0.2 \mathrm{M}$ aqueous $\mathrm{KNO}_{3}$ solution was injected into the cell; the $\mathrm{N}-\mathrm{O}$ stretching peak of the nitrate anion at $1348 \mathrm{~cm}^{-1}$ was used to normalize all spectra, in order to correct for differences in optical pathlength. Normalized adsorption curves were analyzed using commercial software (Igor Pro) as described in detail in the Supporting Information. 


\section{Results}

\subsection{Characterization of amorphous carbon films}

In order to investigate the role played by the composition of amorphous carbon films in the rate of pNBD grafting we investigated the spontaneous grafting of pNBD on three carbon substrates with different $\mathrm{sp}^{2}$ content. Figure 1a shows the Raman spectra of the three different films used for our experiments: a-C, a-C:H1 and a-C:H2. The Raman spectrum of glassy carbon, a noncrystalline $100 \% \mathrm{sp}^{2}$ reference material, ${ }^{40}$ is shown in the Supporting Information for comparison. All substrates show the D and $\mathrm{G}$ bands characteristic of disordered carbon materials. ${ }^{22}$ The D mode centered at $1350 \mathrm{~cm}^{-1}$, has been attributed to the breathing of aromatic carbon rings in graphitic clusters; ${ }^{41}$ this mode is symmetryforbidden in perfect graphite but becomes active in the presence of disorder. The $\mathrm{G}$ mode is centered between 1550 and $1630 \mathrm{~cm}^{-1}$ and arises from the in-plane bond-stretching of $\mathrm{sp}^{2}$ carbon atoms in either aromatic rings or olefinic chains. ${ }^{41}$

$\mathrm{D}$ and $\mathrm{G}$ peak positions, intensities and FWHMs have been shown to depend on the $\mathrm{sp}^{2} / \mathrm{sp}^{3}$ composition of amorphous carbon films. A fit of the D and G peaks with Lorentzian and Breit-WignerFano lines, respectively, ${ }^{42,43}$ for a-C films used in our experiments yielded a $\mathrm{G}$ peak position of 1555 $\mathrm{cm}^{-1}$ and a peak height ratio $\mathrm{I}(\mathrm{D}) / \mathrm{I}(\mathrm{G})$ of 0.34 . The three-stage model proposed by Ferrari and Robertson $^{41}$ for correlating $\mathrm{G}$ peak positions and $\mathrm{I}(\mathrm{D}) / \mathrm{I}(\mathrm{G})$ ratios to $\mathrm{sp}^{2}$ content, suggests that a-C carbon films have an $\mathrm{sp}^{2}$ content in the range $85-90 \%$.

Raman spectra of hydrogenated films display D and G bands over a significant background intensity. This background is a common feature in hydrogen-doped films; it is caused by photoluminescence (PL) due to hydrogen saturation of nonradiative recombination centers ${ }^{44,45}$ and typically increases with $\mathrm{H}$ content. $^{46,47}$ a-C:H2 samples were found to have the highest PL intensities, thus confirming that higher $\mathrm{H}_{2}$ partial pressures during deposition led to increased hydrogen incorporation into the films. The presence of a significant D peak contribution for a-C:H1 samples shows that $\mathrm{sp}^{2}$ centers are still organized in aromatic rings. ${ }^{22}$ Total $\mathrm{sp}^{2}$ as well as graphitic $\mathrm{sp}^{2}$ contents appear to be greatly reduced in a-C:H2 samples, given the small D and G peak signals obtained under similar conditions. 
Raman and Infrared spectroscopy can provide semiquantitative information on the hydrogen content in a-C:H1 and a-C:H2 films. ${ }^{44,46,47}$ In order to directly compare our results with existing models for the interpretation of Raman spectra of hydrogenated carbons, D and G bands were fitted with Gaussian lines ${ }^{46,47}$ yielding a $G$ peak position at $1560 \mathrm{~cm}^{-1}$ for both samples, and $\mathrm{I}(\mathrm{D}) / \mathrm{I}(\mathrm{G})$ ratios of 0.63 and 0.20 for a-C:H1 and a-C:H2, respectively. The PL slope normalized to the $\mathrm{G}$ peak height at $514 \mathrm{~nm}$ excitation, indicated as $m / I(G)$, can be used to estimate the $\mathrm{H}$ content of our films, which was found to vary in the range 30-32\% for a-C:H1 and 40-57\% for a-C:H2, depending on the choice of empirical model used for the calculation. ${ }^{46,47}$ The $G$ peak position value and $I(D) / I(G)$ ratio of a-C:H1 samples shows an excellent agreement with empirical trends observed by Ferrari and Robertson for hydrogenated carbons ${ }^{48}$ we therefore used their results to estimate an $\mathrm{sp}^{2}$ content in the range $60-70 \%$ for a-C:H1 samples. $^{22,48}$ This was not possible in the case of a-C:H2 samples due to their extremely high hydrogen content, since single wavelength Raman models tend to work best for H-content in the range $20-40 \%{ }^{44}$

Figure $1 \mathrm{~b}$ shows infrared spectra of $\mathrm{a}-\mathrm{C}, \mathrm{a}-\mathrm{C}: \mathrm{H} 1$ and $\mathrm{a}-\mathrm{C}: \mathrm{H} 2$ samples in the $\mathrm{C}-\mathrm{H}$ stretching region; spectra were normalized by film thickness in order to obtain an absorptivity value $\alpha$. The spectra of a$\mathrm{C}: \mathrm{H} 1$ and a-C:H2 display a broad contribution centered at approximately $2900 \mathrm{~cm}^{-1}$ which is assigned to both $\mathrm{sp}^{3}\left(2800-2975 \mathrm{~cm}^{-1}\right)$ and $\mathrm{sp}^{2}\left(2975-3000 \mathrm{~cm}^{-1}\right) \mathrm{C}-\mathrm{H}$ stretching modes. ${ }^{22}$ The absence of contributions above $3000 \mathrm{~cm}^{-1}$, which are typically assigned to aromatic $\mathrm{C}-\mathrm{H}$ stretching modes, ${ }^{22}$ indicates that the vast majority of hydrogen atoms are bonded exclusively to $\mathrm{sp}^{3}$ or olefinic $\mathrm{sp}^{2}$ centers in the film. The a-C sample, as expected, does not display $\mathrm{C}-\mathrm{H}$ stretching absorption peaks (the sharp peaks observed in the spectrum are due to residual water vapor in the sample compartment). The integrated areas associated to $\mathrm{C}-\mathrm{H}$ stretching absorptions can be used to obtain relative estimates for bonded hydrogen contents, which were found to be in the ratio $1.9: 1$ for a-C:H2 : a-C:H1.

An increase in $\mathrm{H}$ content is usually accompanied by a decrease in the $\mathrm{sp}^{2}$ content in amorphous carbons due to the saturation of $\mathrm{sp}^{2}$ centers via formation of $\mathrm{C}-\mathrm{H}$ bonds. It is possible to qualitatively examine changes in $\mathrm{sp}^{2}$ content by obtaining Tauc bandgap $\left(\mathrm{E}_{\mathrm{T}}\right)$ values for all three carbon films: ${ }^{23,49} \mathrm{E}_{\mathrm{T}}$ values have been found to increase linearly as $\mathrm{sp}^{2}$ content decreases, while being largely independent 
from H-content that does not lead to changes in hybridization (e.g. interstitial hydrogen). ${ }^{22}$ Tauc bandgap values for a-C, a-C:H1 and a-C:H2 were found to be $0.6 \pm 0.15,1.1 \pm 0.2$ and $1.7 \pm 0.2 \mathrm{eV}$, respectively (see Supporting Information). ${ }^{50,51}$ These results therefore indicate that $\mathrm{sp}^{2}$ content varies in the order a-C > a-C:H1 > a-C:H2; furthermore, based on experimentally identified trends of $\mathrm{E}_{\mathrm{T}}$ vs. $\mathrm{sp}^{2}$ content, ${ }^{22,41}$ a-C and a-C:H1 samples can be estimated to have $\mathrm{sp}^{2}$ contents of $85-90 \%$ and $55-65 \%$.

XPS spectra were used to characterize the composition of these films. ${ }^{52-54}$ Survey scans (see Supporting Information) show the presence of carbon (at $284 \mathrm{eV}$ ) and oxygen (at $532 \mathrm{eV}$ ) in all of the samples, whereas the absence of any peaks around $400 \mathrm{eV}$ indicates that no nitrogen is incorporated into the films during deposition. Figure 2 shows XPS spectra in the $\mathrm{C}$ 1s region for a-C, a-C:H1 and a-C:H2 films; the C 1s spectrum of GC samples is reported in the Supporting Information for comparison. All three samples display a single asymmetric peak that is characteristic of amorphous carbons. Peak asymmetry arises from the presence of carbon atoms in $\mathrm{sp}^{2}$ and $\mathrm{sp}^{3}$ bonding configurations at binding energies separated by $0.7-0.9 \mathrm{eV},{ }^{54,55}$ from energy losses and from the presence of small amounts of surface oxides. ${ }^{53,55}$ The main peak position in our samples gradually increases from $284.4 \mathrm{eV}$ for a-C to $285.1 \mathrm{eV}$ for a-C:H2 as would be expected from a decrease in $\mathrm{sp}^{2} / \mathrm{sp}^{3}$ ratio upon hydrogen doping. Fits of the $\mathrm{C}$ 1s peak of a-C and a-C:H1 samples yielded two main contributions at 284.4 and $285.1 \mathrm{eV}$ that we assign to $\mathrm{sp}^{2}$ and $\mathrm{sp}^{3}$ carbon centers, respectively, and additional contributions at higher binding energy that we attribute to oxidised groups. The $\mathrm{C} 1 \mathrm{~s}$ spectrum of a-C:H2 was fitted with three peaks, one at $285.1 \mathrm{eV}$ assigned to $\mathrm{sp}^{3}$ carbons and a two additional ones at higher binding energy. The relative area contribution of the $\mathrm{sp}^{3}$ peak has been shown to provide good estimates for the bulk concentration of $\mathrm{sp}^{3}$ centers. ${ }^{54}$ In the case of our samples the relative peak area $\mathrm{A}(285.1) / \mathrm{A}_{\text {TOт }}$ was found to be $20 \pm 4 \%$, $38 \pm 11 \%$ and $83 \pm 4 \%$ for a-C, a-C:H1 and a-C:H2, respectively. These values are consistent with estimates of bulk $\mathrm{sp}^{2}$ content of $85-90 \%$ and $55-70 \%$ for a-C and a-C:H1 obtained from Raman and $\mathrm{E}_{\mathrm{T}}$ values (see above). The oxygen content was found to be approximately $9 \%$ for all of the carbon surfaces used in our experiments (see Supporting Information for a summary of individual O/C\% values). 
Finally, surface morphology is important in order to compare the rate of reactions occurring at surfaces, we therefore characterized the roughness of the carbon surfaces via Atomic Force Microscopy (AFM). All amorphous carbons used were found to be quantitatively similar, with RMS roughness values for films deposited on polished Si wafers of $1.8 \pm 0.6,1.8 \pm 0.1$ and $2.9 \pm 0.6 \mathrm{~nm}$, for a-C, a$\mathrm{C}: \mathrm{H} 1$ and $\mathrm{a}-\mathrm{C}: \mathrm{H} 2$, respectively.

\subsection{In situ spectroscopic characterization of pNBD adsorption rate}

In order to investigate whether amorphous carbon composition affects pNBD adsorption rates we performed ATR-FTIR spectroscopy measurements. This technique can be used to monitor in situ, the growth of films on surfaces; ${ }^{.6}$ in our case, carbon-coated Si trapezoids were mounted in the liquid cell with the carbon coated side exposed to the liquid in order to monitor spectroscopic changes at their interface. $^{57}$

Background spectra were collected at the beginning of each run with water in the cell; after injection of pNBD, spectra were collected for $3 \mathrm{~h}$. Figure $3 \mathrm{a}$ shows an example of a raw absorbance spectrum obtained from a pNBD-grafted a-C film after $120 \mathrm{~min}$. The two peaks at 1524 and $1348 \mathrm{~cm}^{-1}$ are assigned to the asymmetric and symmetric stretching modes of the nitro group. Control experiments on bare Si trapezoids immersed in pNBD solutions showed that, at the same bulk pNBD concentrations used for our experiments, the absorbance contribution of molecules in solution could not be detected. Therefore, the peaks observed in Figure 3 a originate from an excess of pNBD molecules at the carbon surface, and any increase observed in $-\mathrm{NO}_{2}$ absorbances were exclusively attributed to an increase in adsorbed nitrophenyl groups.

The net absorbance of the symmetric $\mathrm{N}=\mathrm{O}$ stretching at approximately $1348 \mathrm{~cm}^{-1}$ was used to monitor the deposition of pNBD over time. The symmetric mode was chosen because it is the least affected by interference from atmospheric water vapour peaks, thus facilitating the analysis. Figure $3 b$ shows a representative time evolution of the $1348 \mathrm{~cm}^{-1}$ line after injection of a $1 \times 10^{-4} \mathrm{M}$ pNBD solution into the ATR-FTIR cell using a-C coated trapezoids. The net absorbance at $\sim 1348 \mathrm{~cm}^{-1}$ was calculated for every 
spectrum, normalized by the cell pathlength and plotted as a function of deposition time, thus allowing for an analysis of the relative pNBD grafting rates and yields on all a-C films. Figure $3 \mathrm{c}$ shows typical curves for the surface modification of a-C, a-C:H1 and a-C:H2 films from $1 \times 10^{-4} \mathrm{M}$ aqueous pNBD solutions. Figure $3 \mathrm{~b}$ indicates that the adsorption yield at any time during deposition is highest for a-C and decreases in the order a-C $>$ a-C:H1 $>$ a-C:H2. This result suggests that a decrease in $\mathrm{sp}^{2} / \mathrm{sp}^{3}$ ratio leads to decreased deposition yields under the same experimental conditions.

Figure $3 \mathrm{c}$ shows that at early times there is a rapid increase in pNBD surface coverage; this rapid first step is followed by a much slower rate of accumulation thus suggesting the presence of at least two phases in the adsorption kinetics. This observation is in agreement with previous work by Lehr and Downard, ${ }^{35}$ who identified two similar deposition regimes during spontaneous grafting of pNBD on glassy carbon via open circuit potential measurements. For a-C samples, pNBD adsorption levels off after approximately $120 \mathrm{~min}$, whereas for hydrogenated samples the adsorption process continues beyond $3 \mathrm{~h}$.

In order to obtain a relative measure of the initial rate of adsorption of $\mathrm{pNBD}$ at different carbon surfaces, we carried out straight line fits of the normalized adsorption curves obtained via ATR-FTIR in the region 0-1 $\min$ (see Supporting Information). Figure 4 shows a summary of rates obtained from linear fits of the earliest deposition regimes; the rate constants are displayed vs. the $\mathrm{E}_{\mathrm{T}}$ value of the associated carbon sample. The results summarized in Figure 4 show a strong dependence of adsorption rates on $\mathrm{E}_{\mathrm{T}}$; given the linear correlation between $\mathrm{E}_{\mathrm{T}}$ values and $\mathrm{sp}^{2}$ bulk content in amorphous carbons, ${ }^{22}$ our results suggest a decrease in rate with decreasing $\mathrm{sp}^{2}$ content in the carbon bulk.

\subsection{Electrochemical characterization of spontaneous pNBD grafting}

ATR-FTIR measurements provide relative measurements of pNBD deposition rates in situ and in real time for three forms of amorphous carbons, however, it is useful to quantitatively compare these results with those obtained on a reference material with $100 \% \mathrm{sp}^{2}$ content. Therefore, we carried out electrochemical studies of pNBD deposition at glassy carbon and at amorphous carbon films deposited 
on stainless steel substrates. The grafting of pNBD and other aryldiazonium salts on glassy carbon (GC) has been studied extensively in the literature; hence, we used GC electrodes as a reference substrate in order to compare results obtained at a-C electrodes. GC is a highly graphitic material ${ }^{58,59}$ consisting of $^{5}$ $100 \% \mathrm{sp}^{2}$ carbon and is therefore a useful term of reference for understanding the role of $\mathrm{sp}^{2}$ centers on the grafting process. The grafting of pNBD on the different carbons was investigated via cyclic voltammetry by examining the electroreduction of nitrophenyl to phenylamine groups. The yield of the grafting reaction was determined at different deposition times by measuring the area-normalized charge required for the electroreduction of surface bound $\mathrm{ArNO}_{2}$ moieties. ${ }^{33,60-62}$

First, we tested whether sputtered carbon films could be used as working electrodes for cyclic votammetry $(\mathrm{CV})$ experiments by investigating their electrochemical response in solutions containing $\mathrm{Ru}\left(\mathrm{NH}_{3}\right)_{6}{ }^{3+/ 2+}$ and $\mathrm{Fe}(\mathrm{CN})_{6}^{3-/ 4-}$, two reversible redox couples which are often used for evaluating the response of carbon electrodes. ${ }^{63}$ The $\mathrm{CV}$ obtained at $0.075 \mathrm{~V} \mathrm{~s}^{-1}$ for unmodified a-C in these solutions (see Supporting Information) displays the characteristic redox waves of $\mathrm{Ru}\left(\mathrm{NH}_{3}\right)_{6}{ }^{3+/ 2+}$ and $\mathrm{Fe}(\mathrm{CN})_{6}{ }^{3-/ 4-}$, with nearly reversible peak-to-peak separations of $72 \pm 2$ and $76 \pm 5 \mathrm{mV}$, respectively. The peak current of these CVs was found to vary linearly with the square root of the potential sweep rate, thus suggesting that a-C electrodes display reversible response. ${ }^{64}$ Hydrogenated samples a-C:H1 and a-C:H2 were found to be too resistive to be used as working electrodes and could not be characterized via CV.

GC and a-C electrodes were immersed in pNBD aqueous solutions in order to spontaneously graft $\mathrm{ArNO}_{2}$ moieties on these substrates. At regular time intervals the carbon samples were removed from the deposition solution, rinsed and characterized via $\mathrm{CV}$ in $0.1 \mathrm{M} \mathrm{H}_{2} \mathrm{SO}_{4}$ solutions. Figure 5a shows a typical $\mathrm{CV}$ obtained in $0.1 \mathrm{M} \mathrm{H}_{2} \mathrm{SO}_{4}$ at $0.2 \mathrm{~V} \mathrm{~s}^{-1}$, on a-C electrodes after spontaneous grafting in $6 \times 10^{-4}$ $\mathrm{M}$ pNBD solutions. The CV displays an irreversible reduction peak at $-0.54 \mathrm{~V}$ vs. $\mathrm{Ag} / \mathrm{AgCl}$ that is characteristic of nitrophenyl reductions, ${ }^{62}$ a $6 \mathrm{e}^{-}$reduction process. ${ }^{60}$ The near complete absence of the reduction peak after a second sweep indicates that the majority of nitrophenyl groups are reduced during the first cycle. The appearance of a reversible couple at $\mathrm{E}_{1 / 2}=0.32 \mathrm{~V}$ on the oxidative sweep is 
attributed to the hydroxyaminophenyl/nitrosophenyl interconversion; this peak, therefore, indicates that not all of the nitrophenyl groups undergo a full $6 \mathrm{e}^{-}$reduction to aminophenyl groups.

The total charge passed during nitrophenyl reduction and hydroxyaminophenyl oxidation can be obtained via peak integration and normalized to the electrode area, in order to yield the surface coverage of nitrophenyl groups present at the carbon surface, $\Gamma_{\mathrm{NP}}{ }^{62}$ Figure $5 \mathrm{~b}$ shows $\Gamma_{\mathrm{NP}}$ values thus calculated, as a function of immersion time in $6 \times 10^{-4} \mathrm{M}$ pNBD on a-C and GC samples. During the first 10 min of the deposition, $\Gamma_{\mathrm{NP}}$ increases more rapidly for GC electrodes; after longer deposition times the value of $\Gamma_{\mathrm{NP}}$ levels off for both substrates. The value of $\Gamma_{\mathrm{NP}}$ on GC after $10 \mathrm{~min}$ of immersion is $13.2 \times 10^{-10}$ $\mathrm{mol} / \mathrm{cm}^{2}$ whereas $\Gamma_{\mathrm{NP}}$ on a-C substrates after the same immersion time was found to be $58 \%$ of this value, at $7.7 \times 10^{-10} \mathrm{~mol} / \mathrm{cm}^{2}$. Straight line fits of $\Gamma_{\mathrm{NP}}$ curves in the range $0-1 \mathrm{~min}$ yielded initial rates for pNBD deposition at a-C and GC electrodes of $8.9 \times 10^{-10}$ and $1.8 \times 10^{-9} \mathrm{~mol} \mathrm{~cm}^{-2} \mathrm{~min}^{-1}$, respectively. These differences in calculated $\Gamma_{\mathrm{NP}}$ and initial rates at $\mathrm{GC}$ and a-C surfaces could originate from differences between the microscopic roughness of the two electrodes. In order to examine this possibility we carried out AFM roughness determinations on both GC and a-C electrodes. The average RMS roughness of GC electrodes was $5.8 \pm 1.3 \mathrm{~nm}$; this value is in good agreement with previous roughness determinations of polished GC samples. ${ }^{65}$ The average RMS roughness of a-C electrodes was found to be $16 \pm 8 \mathrm{~nm}$, higher than that measured on Si wafers (see above), due to the higher roughness of the underlying stainless steel. If the observed differences in $\Gamma_{\mathrm{NP}}$ or initial rates were due to differences in the microscopic area available for grafting, we would expect a-C electrodes to display higher apparent $\Gamma_{\mathrm{NP}}$, which is the opposite of what is observed in Figure 5a. Roughness results therefore suggest that other factors must be at the origin of differences in grafting rates and yields between GC and a-C.

It has been shown that the first step in the attachment of aryldiazonium groups on carbon nanotubes and graphene consists of a charge-transfer mediated adsorption of aryldiazonium molecules onto the carbon surface. ${ }^{12,18,20}$ Charge transfer rates on graphitic carbon electrodes are known to strongly depend on edge plane density, since edge sites can (a) increase the density of states near the Fermi energy and 
(b) also introduce chemical groups that facilitate adsorption. ${ }^{63,66,67}$ We therefore decided to investigate whether differences in pNBD grafting rates or yields between GC and a-C electrodes could be correlated to differences in edge plane density. In order to do this we chose a method developed by Compton and coworkers $^{36,68}$ based on the partial intercalation of 4-NBA between graphite basal planes, a process that takes place at exposed edge plane sites. The interlayer spacing in graphite does not allow for a full intercalation to take place; hence, $\mathrm{Ph}-\mathrm{NO}_{2}$ moieties remain exposed to the electrolyte at the carbon/solution interface, and can be reduced electrochemically to yield a measure of the amount of intercalated 4-NBA.

GC and a-C electrodes were immersed for $2 \mathrm{~h}$ in acetonitrile solutions of 4-NBA, then rinsed and tested via CV. Figure 6 shows typical CVs of GC and a-C electrodes after 4-NBA intercalation obtained in $0.1 \mathrm{M} \mathrm{H}_{2} \mathrm{SO}_{4}$ at $0.2 \mathrm{~V} \mathrm{~s}^{-1}$. Voltammetric waves are similar to those obtained with nitrophenyl groups immobilized via diazonium chemistry. The charge associated to the electroreduction peak was integrated in order to obtain an estimate of surface coverage for intercalated 4-NBA, $\Gamma_{\mathrm{NBA}}$, yielding values of (5.9 $\pm 2.5) \times 10^{-10}$ and $(3.4 \pm 0.9) \times 10^{-10} \mathrm{~mol} \mathrm{~cm}^{-2}(95 \%$ C.I. $)$ for $\mathrm{GC}$ and a-C, respectively. The value of $\Gamma_{\mathrm{NBA}}$ at a-C electrodes is approximately $58 \%$ of that obtained at GC electrodes, thus suggesting that $\Gamma_{\mathrm{NP}}$ values track the intercalation results for $\Gamma_{\mathrm{NBA}}$.

In summary, a comparison of pNBD grafting rates and yields between GC and a-C shows that GC electrodes display significantly higher $\Gamma_{\mathrm{NP}}$ than a-C electrodes under the same deposition conditions. The observed difference in coverage cannot be explained by differences in surface roughness, thus indicating that other factors are at the origin of these results. The intercalation of 4-NBA, which is sensitive to the density of exposed edge planes at carbon surfaces, was found to positively correlate with diazonium grafting results. In fact, the relative ratio $\Gamma_{\mathrm{NP}}(\mathrm{a}-\mathrm{C}) / \Gamma_{\mathrm{NP}}(\mathrm{GC})=0.58$ was found to be in excellent agreement with that of $\Gamma_{\mathrm{NBA}}(\mathrm{a}-\mathrm{C}) / \Gamma_{\mathrm{NBA}}(\mathrm{GC})=0.58$. This result suggests that the surface density of graphitic edge planes at a-C amorphous carbon films is an important factor in controlling pNBD grafting yields. 


\section{Discussion}

The rates of spontaneous grafting of pNBD were investigated on three types of amorphous carbons with similar roughness and oxygen content but with significantly different $\mathrm{sp}^{2} / \mathrm{sp}^{3}$ and hydrogen contents. The three amorphous carbons used in our experiments possess decreasing $\mathrm{sp}^{2}$ content in the order a-C > a-C:H1 > a-C:H2; these changes in $\mathrm{sp}^{2}$ content were achieved by introducing hydrogen into the films also resulting in an opening of the optical bandgap of these materials. The hydrogen content increased in the order $\mathrm{a}-\mathrm{C}<\mathrm{a}-\mathrm{C}: \mathrm{H} 1<\mathrm{a}-\mathrm{C}: \mathrm{H} 2$ as seen via infrared and Raman spectroscopy. It was found that modifying carbon composition resulted in dramatic changes in pNBD adsorption rates, which were compared to those observed at GC surfaces. A combination of electrochemical ex situ experiments and spectroscopic in situ experiments shows that the pNBD adsorption yields and initial rates follow the order $\mathrm{GC}>\mathrm{a}-\mathrm{C}>\mathrm{a}-\mathrm{C}: \mathrm{H} 1>\mathrm{a}-\mathrm{C}: \mathrm{H} 2$.

The mechanism of spontaneous attachment of aryldiazonium cations on carbon materials has been the subject of intense investigation. Strano and co-workers ${ }^{12,13,20}$ developed a kinetic model in which the first step in the covalent grafting at nanotube and graphene surfaces consists of a first order adsorption of aryldiazonium cations via formation of a charge-transfer complex. The adsorbed complex subsequently decomposes into the covalently bonded species losing dinitrogen. The adsorption process was found to be sensitive to the metallic character of nanotubes, with reactivity decreasing with increasing bandgap. This behavior was explained by considering that adsorption occurs via electron transfer from states near the Fermi energy in the nanotubes to the acceptor level of pNBD in solution, thus explaining the observed decrease in the rate of adsorption with an increase in nanotube bandgap.

The validity of this mechanism has not been directly probed for other types of carbon. It has been observed that pNBD layers grafted on GC via electroreduction and spontaneous attachment have similar structures and it has been proposed that, in both cases, grafting occurs via pNBD reduction and loss of dinitrogen. ${ }^{28}$ The role of charge-transfer mediated adsorption, however, has not been explored in this type of materials. The results obtained in our experiments suggest that the model developed by Strano and co-workers for nanotubes could be valid for disordered carbons as well. Under their kinetic 
hypothesis the expected reactivity trend for the spontaneous grafting would be that of decreasing reaction rates with a decrease in the metallic character of carbon surfaces. We have observed similar trends in our experiments, as shown by data in Figure 4 and Figure 7. Glassy carbon, which can be described as a semimetal with near-zero optical bandgap and high conductivity, ${ }^{69}$ displayed the fastest adsorption rates relative to a-C, a-C:H1 and a-C:H2. The second highest rate was that of a-C substrates, which behave as good conductors and have a small optical bandgap of $\sim 0.5 \mathrm{eV}$. Hydrogenated samples were shown to behave as poor conductors and also display the lowest grafting rates, in agreement with trends in spontaneous grafting on nanotubes. Importantly, the same general trend was observed independently of whether the adsorption rates are plotted vs. bulk $\mathrm{sp}^{2}$ content $\left(\mathrm{E}_{\mathrm{T}}\right.$ values) as in Figure 4 , or vs. surface $\mathrm{sp}^{2}$ content, as in Figure 7.

The optical bandgap offers a useful parameter for a qualitative evaluation of the metallic character of amorphous carbons, however, it does not define a gap in the density of states (DOS) as in the case of ordered semiconductors. Localized states near the Fermi energy can exist even for wide bandgap amorphous carbons and their contribution to electron-transfer mediated adsorption reactions should be considered in order to develop structure reactivity relationships for these materials. ${ }^{70}$ The $\mathrm{sp}^{2}$ content of amorphous carbons should be a better parameter than $E_{T}$ for rationalizing reaction trends, since $\mathrm{sp}^{2}$ carbon centers contribute to $\pi$ states which lie close to the Fermi energy. ${ }^{69}$ These states are directly involved in electron transfer reactions at the surface and their role in pNBD adsorption could be important, regardless of their degree of delocalization and their effect on $\mathrm{E}_{\mathrm{T}}$ values.

Intercalation experiments, that directly probe the exposed graphitic edge plane density provide support for a strong positive correlation between graphitic $\mathrm{sp}^{2}$ content and $\mathrm{pNBD}$ grafting yields. Work by Toupin and Belanger ${ }^{71}$ on spontaneous pNBD grafting on carbon black samples reported that the limiting coverage of aryldiazonium is similar to their estimated value of edge plane coverage at these carbon nanoparticles. These previous results, together with our intercalation and grafting experiments, indicate that high graphitic $\mathrm{sp}^{2}$ content is a strong predictor of high $\mathrm{pNBD}$ grafting yields. 
The relation between $\mathrm{sp}^{2}$ content and reaction rates is of greater complexity. Figure 7 shows a summary of the initial rates of pNBD deposition, relative to that at a-C:H2, at the four different carbon surfaces used in our experiments; the plot shows the dependence of rates vs. $\mathrm{sp}^{2}$ content as measured by XPS. The relative rate of adsorption at $\mathrm{GC}$, which consists of $100 \% \mathrm{sp}^{2}$ carbon, was obtained from the ex situ electrochemical measurements in Figure 5. It is clear from this graph that there is a strong dependence of the $\mathrm{pNBD}$ initial attachment rate on $\mathrm{sp}^{2}$ content. A first conclusion that emerges from Figure 7 is that a-C:H2 samples, despite having only a very small $\mathrm{sp}^{2}$ content, still show a significant rate of attachment. This is in agreement with experimental reports that demonstrate that pNBD spontaneously grafts at $100 \% \mathrm{sp}^{3}$ surfaces, ${ }^{30,72}$ and indicates that $\mathrm{pNBD}$ attachment is possible, albeit at a slow rate, even at low $\mathrm{sp}^{2}$ content. A second important observation is that the initial rate does not vary linearly with $\mathrm{sp}^{2}$ content. Assuming first order Langmuirian kinetics for the reaction and even in the case of multilayer growth, ${ }^{73,74}$ the nitrophenyl coverage, $\Gamma$, can be approximated at $t \approx 0$ as:

$$
\Gamma=k \Gamma_{\max }[\mathrm{pNBD}] t
$$

where $\Gamma_{\max }$ is the limiting coverage, $[\mathrm{pNBD}]$ is the bulk concentration of $\mathrm{pNBD}$ and $k$ is the rate constant. If the initial deposition rate increased with $\mathrm{sp}^{2}$ content because of an increase in $\mathrm{sp}^{2}$ sites at the surface, then a linear dependence would be expected for Figure 7. The fact that non-linear behavior is observed suggests that the plot in Figure 7 does not reflect solely an increase in the area covered by $\mathrm{sp}^{2}$ sites at the carbon surface.

Experimental and theoretical work on aryldiazonium electrografting at highly ordered pyrolytic graphite (HOPG) has shown that edge planes display faster electrografting rates than basal planes. ${ }^{75-77}$ The greater reactivity of graphitic edges has been explained in terms of their effect on the carbon valence electronic structure. Dangling $\pi$ bonds at edge defects on HOPG introduce localized states, ${ }^{78-80}$ leading to a significant increase in the density of states (DOS) at the Fermi energy. It is this greater DOS at graphite steps that gives rise to the larger double-layer capacitance and electron transfer rates of edge vs. basal plane electrodes. ${ }^{63,81}$ The effect of $\mathrm{sp}^{2}$ sites and, more specifically, of graphitic edges on the rate of attachment might be felt over a much larger area than the geometric area occupied at the surface. 
This has been previously observed by McDermott and McCreery for the adsorption of quinones at HOPG and GC electrodes. ${ }^{81}$ They reported that adsorption of quinones at graphitic step edges was promoted over a vast area adjacent to the step, and concluded that the adsorption was largely controlled by the enhanced electron density associated with the step, which acted as a perturbation over an area vastly larger than the geometric area.

We hypothesize that the trends observed in Figure 7 could reflect changes in the carbon DOS and consequently in the overlap between donor states at the carbon and acceptor states of pNBD molecules, as observed by Sharma et al. for the rate of aryldiazonium grafting at graphene. ${ }^{20}$ As the amount of $\mathrm{sp}^{2}$ carbon in the films increases it is more probable for $\mathrm{sp}^{2}$ centers to give rise to graphitic clusters with highly reactive edges exposed at the surface and a consequent increase in the DOS near the Fermi energy. ${ }^{82}$ This mechanism could be important even in the case of highly hydrogenated samples, since previous reports show that the $\mathrm{sp}^{2}$ centers in sputtered hydrogenated carbons are graphitic in nature. ${ }^{83}$ In order to achieve a better understanding of the effect of $\mathrm{sp}^{2}$ concentration on spontaneous surface reactions with aryldiazonium it would be desirable to have detailed information on the carbon DOS for the different films such as that obtained via valence photoemission experiments.

\section{Conclusions}

We investigated the kinetics of adsorption of pNBD at four different carbon surfaces with drastically different $\mathrm{sp}^{2}$ content. Infrared spectroscopic methods allowed for the first time to obtain $\mathrm{pNBD}$ adsorption curves in situ and in real time, even for forms of carbon that cannot be characterized electrochemically. We have found that the adsorption of pNBD is enhanced by an increase in the metallic character of the amorphous carbons and that there is a strong non-linear dependence of the initial adsorption rates on the $\mathrm{sp}^{2}$ content. We hypothesize that this is due to the increased density of graphitic clusters with increased $\mathrm{sp}^{2}$ content in the amorphous carbon leading, in turn, to an enhanced DOS close to the carbon Fermi energy. This is consistent with intercalation experiments showing that grafting yields at early deposition times mirror the coverage of graphitic edge planes. 
These results suggest that the kinetic model of the spontaneous grafting of aryldiazonium salts that involves a charge-transfer mediated adsorption step is applicable not only to ordered carbon nanomaterials, but might be extended to carbons in general. Therefore, by analogy with previous nanotube applications, it is possible to envision leveraging spontaneous aryldiazonium reactions at carbon surfaces as a strategy for the characterization and selection/separation of disordered carbons based on their electronic properties. Such a methodology would be a valuable tool for the numerous applications of disordered carbons, such as those in heterogeneous catalysis and adsorption, that rely on their surface electronic properties.

Acknowledgements. This publication has emanated from research conducted with the financial support of Science Foundation Ireland under Grant Number 09/RFP/CAP2174 and of the Irish Council for Science Engineering and Technology (IRCSET) under the Postdoctoral Fellowship Scheme. JC and GD were supported by the Science Foundation Ireland SURE programme under Grant Number 08/UR/I1351. The authors are grateful to Dr. Cormac McGuinness, Prof. Igor Shvets, Dr. Michael E.G. Lyons, Dr. Silvia Giordani and Dr. Tania Perova for kindly providing access to instrumentation.

Supporting Information Available. Tauc plots, Raman and XPS spectra of GC, XPS survey scans and $\mathrm{O} 1 \mathrm{~s}$ analysis, cyclic voltammetry on bare a-C electrodes and details of fitting procedures. This material is available free of charge via the Internet at http://pubs.acs.org. 


\section{References}

1. Serp, P.; Figueiredo, J. L., Carbon Materials for Catalysis. John Wiley \& Sons: Hoboken, New Jersey, 2009.

2. Sun, J. T.; Hong, C. Y.; Pan, C. Y., Polym. Chem. 2011, 2, 998.

3. Schrand, A. M.; Hens, S. A. C.; Shenderova, O. A., Crit. Rev. Solid State Mater. Sci. 2009, 34, 18.

4. Karousis, N.; Tagmatarchis, N.; Tasis, D., Chem. Rev. 2010, 110, 5366.

5. Koehler, F. M.; Luechinger, N. A.; Ziegler, D.; Athanassiou, E. K.; Grass, R. N.; Rossi, A.; Hierold, C.; Stemmer, A.; Stark, W. J., Angew. Chem., Int. Ed. 2009, 48, 224.

6. Qi, D.; Chen, W.; Gao, X.; Wang, L.; Chen, S.; Loh, K. P.; Wee, A. T. S., J. Am. Chem. Soc. 2007, 129,8084 .

7. Qi, D.; Gao, X.; Wang, L.; Chen, S.; Loh, K. P.; Wee, A. T. S., Chem. Mater. 2008, 20, 6871.

8. Wang, X. R.; Li, X. L.; Zhang, L.; Yoon, Y.; Weber, P. K.; Wang, H. L.; Guo, J.; Dai, H. J., Science 2009, 324, 768 .

9. Zhou, S. Y.; Siegel, D. A.; Fedorov, A. V.; Lanzara, A., Phys. Rev. Lett. 2008, 101, 086402.

10. Nosho, Y.; Ohno, Y.; Kishimoto, S.; Mizutani, T., Nanotechnology 2007, 18, 415202.

11. Strano, M. S.; Dyke, C. A.; Usrey, M. L.; Barone, P. W.; Allen, M. J.; Shan, H. W.; Kittrell, C.; Hauge, R. H.; Tour, J. M.; Smalley, R. E., Science 2003, 301, 1519.

12. Usrey, M. L.; Lippmann, E. S.; Strano, M. S., J. Am. Chem. Soc. 2005, 127, 16129.

13. Nair, N.; Kim, W.-J.; Usrey, M. L.; Strano, M. S., J. Am. Chem. Soc. 2007, 129, 3946.

14. Baik, S.; Usrey, M.; Rotkina, L.; Strano, M. S., J. Phys. Chem. B 2004, 108, 15560.

15. Kim, W. J.; Usrey, M. L.; Strano, M. S., Chem. Mater. 2007, 19, 1571.

16. An, L.; Fu, Q.; Lu, C.; Liu, J., J. Am. Chem. Soc. 2004, 126, 10520.

17. Balasubramanian, K.; Sordan, R.; Burghard, M.; Kern, K., Nano Lett. 2004, 4, 827.

18. Koehler, F. M.; Jacobsen, A.; Ensslin, K.; Stampfer, C.; Stark, W. J., Small 2010, 6, 1125.

19. Sharma, R.; J.H., B.; C.J., P.; M.S., S., Nano Lett. 2010, 10, 398.

20. Sharma, R.; Nair, N.; Strano, M. S., J. Phys. Chem. C 2009, 113, 14771.

21. Pierson, H. O., Handbook of Carbon, Graphite, Diamond and Fullerenes - Properties, Processing and Applications 1st ed.; Noyes Publications: Park Ridge, New Jersey, 1993.

22. Robertson, J., Mater. Sci. Eng., R 2002, 37, 129. 
23. Silva, S. R. P., Properties of amorphous carbon. 1st ed.; INSPEC, Inc. The Institution of Electrical Engineers: London, 2003.

24. Colavita, P. E.; Streifer, J. A.; Sun, B.; Wang, X.; Warf, P.; Hamers, R. J., J. Phys. Chem. C 2008, 112,5102 .

25. Colavita, P. E.; Sun, B.; Tse, K. Y.; Hamers, R. J., J. Am. Chem. Soc. 2007, 129, 13554.

26. Colavita, P. E.; Sun, B.; Wang, X.; Hamers, R. J., J. Phys. Chem. C 2009, 113, 1526.

27. Garrett, D. J.; Lehr, J.; Miskelly, G. M.; Downard, A. J., J. Am. Chem. Soc. 2007, 129, 15456.

28. Barriere, F.; Downard, A. J., J. Solid State Electrochem. 2008, 12, 1231.

29. Pandurangappa, M.; Lawrence, N. S.; Compton, R. G., Analyst 2002, 127, 1568.

30. Yang, W.; Baker, S. E.; Butler, J. E.; Lee, C.-s.; Russell, J. N.; Shang, L.; Sun, B.; Hamers, R. J., Chem. Mater. 2005, 17, 938.

31. Bahr, J. L.; Tour, J. M., Chem. Mater. 2001, 13, 3823.

32. Lomeda, J. R.; Doyle, C. D.; Kosynkin, D. V.; Hwang, W.-F.; Tour, J. M., J. Am. Chem. Soc. 2008, 130, 16201.

33. Adenier, A.; Cabet-Deliry, E.; Chausse, A.; Griveau, S.; Mercier, F.; Pinson, J.; Vautrin-Ul, C., Chem. Mater. 2005, 17, 491.

34. Combellas, C.; Delamar, M.; Kanoufi, F.; Pinson, J.; Podvorica, F. I., Chem. Mater. 2005, $17,3968$.

35. Lehr, J.; Williamson, B. E.; Downard, A. J., J. Phys. Chem. C 2011, 115, 6629.

36. Wildgoose, G. G.; Wilkins, S. J.; Williams, G. R.; France, R. R.; Carnahan, D. L.; Jiang, L.; Jones, T. G. J.; Compton, R. G., ChemPhysChem 2005, 6, 352.

37. Kiema, G. K.; Aktay, M.; McDermott, M. T., J. Electroanal. Chem. 2003, 540, 7.

38. Proctor, A.; Sherwood, P. M. A., Anal. Chem. 1982, 54, 13.

39. Shirley, D. A., Phys. Rev. B 1972, 5, 4709.

40. Bosman, M.; Keast, V. J.; Watanabe, M.; McCulloch, D. G.; Shakerzadeh, M.; Teo, E. H. T.; Tay, B. K., Carbon 2009, 47, 94.

41. Ferrari, A. C.; Robertson, J., Phys. Rev. B 2000, 61, 14095.

42. McCulloch, D. G.; Prawer, S., Appl. Phys. Lett. 1995, 78, 3040.

43. McCulloch, D. G.; Prawer, S.; Hoffman, A., Phys. Rev. B 1994, 50, 5905.

44. Casiraghi, C.; Piazza, F.; Ferrari, A. C.; Grambole, D.; Robertson, J., Diamond Relat. Mater. 2005, $14,1098$.

45. Robertson, J., Phys. Rev. B 1996, 53, 16302. 
46. Casiraghi, C.; Ferrari, A. C.; Robertson, J., Phys. Rev. B 2005, 72, 085401.

47. Buijnsters, J. G.; Gago, R.; Jiménez, I.; Camero, M.; Agulló-Rueda, F.; Gómez-Aleixandre , C., J. Appl. Phys. 2009, 105, 093510.

48. Ferrari, A. C.; Kleinsorge, B.; Adamopoulos, G.; Robertson, J.; Milne, W. I.; Stolojan, V.; Brown, L. M.; LiBassi, A.; Tanner, B. K., J. Non-Cryst. Solids 2000, 266-269, 765.

49. Tauc, J., Amorphous and liquid semiconductors. 1st ed.; Plenum Press: London and New York, 1974.

50. Foulani, A., J. Phys. D: Appl. Phys. 2003, 36, 394.

51. Sun, B.; Colavita, P. E.; Kim, H.; Lockett, M.; Marcus, M. S.; Smith, L. M.; Hamers, R. J., Langmuir 2006, 22, 9598.

52. Kassavetis, S.; Patsalas, P.; Logothetidis, S.; Robertson, J.; Kennou, S., Diamond Relat. Mater. 2007, 16, 1813.

53. Patsalas, P.; Logothetidis, S.; Kennou, S.; Gravalidis, C., Thin Solid Films 2003, 428, 211.

54. Haerle, R.; Riedo, E.; Pasquarello, A.; Baldereschi, A., Phys. Rev. B 2001, 65, 045101.

55. Jackson, S. T.; Nuzzo, R. G., Appl. Surf. Sci. 1995, 90, 195.

56. Xing, R.; Rankin, S. E., J. Phys. Chem. B 2005, 110, 295.

57. Tolstoy, V. P.; Chernyshova, I.; Skryshevsky, V. A., Handbook of Infrared Spectroscopy of Ultrathin Films. John Wiley \& Sons, Inc.: Hoboken, New Jersey, 2003.

58. Jenkins, G. M.; Kawamura, K., Nature 1971, 231, 175.

59. Brown, N. M. D.; You, H. X., J. Mater. Chem. 1991, 1, 469.

60. Delamar, M.; Désarmot, G.; Fagebaume, O.; Hitmi, R.; Pinsonc, J.; Savéant, J. M., Carbon 1997, 35,801 .

61. Allongue, P.; Delamar, M.; Desbat, B.; Fagebaume, O.; Hitmi, R.; Pinson, J.; Savèant, J.-M., J. Am. Chem. Soc. 1997, 119, 201.

62. Brooksby, P. A.; Downard, A. J., Langmuir 2004, 20, 5038.

63. McCreery, R. L., Chem. Rev. 2008, 108, 2646.

64. Kissinger, P. T.; Heineman, W. R., Laboratory techniques in electroanalytical chemistry. 2nd ed.; Marcel Dekker, Inc.: New York, 1996.

65. McDermott, M. T.; McDermott, C. A.; McCreery, R. L., Anal. Chem. 1993, 65, 937.

66. Davies, T. J.; Moore, R. R.; Banks, C. E.; Compton, R. G., J. Electroanal. Chem. 2004, 574, 123.

67. Cline, K. K.; McDermott, M. T.; McCreery, R. L., J. Phys. Chem. 1994, 98, 5314. 
68. Banks, C. E.; Davies, T. J.; Wildgoose, G. G.; Compton, R. G., Chem. Commun. (Cambridge, U. K.) 2005, 829.

69. Robertson, J., Adv. Phys. 1986, 35, 317.

70. Stenzel, O., The physics of thin film optical spectra. Springer Verlag: Berlin, 2005.

71. Toupin, M.; Belanger, D., Langmuir 2008, 24, 1910.

72. Lud, S. Q.; Steenackers, M.; Jordan, R.; Bruno, P.; Gruen, D. M.; Feulner, P.; Garrido, J. A.; Stutzmann, M., J. Am. Chem. Soc. 2006, 128, 16884.

73. Masel, R. I., Adsorption II: Adsorption Isotherms. In Principles of Adsorption and Reaction on Solid Surfaces, John Wiley \& Sons: New York, 1996.

74. Vinokurov, I. A.; Kankare, J., Langmuir 2002, 18, 6789.

75. Jiang, D.-e.; Sumpter, B. G.; Dai, S., J. Phys. Chem. B. 2006, 110, 23628.

76. Kariuki, J. K.; McDermott, M. T., Langmuir 1999, 15, 6534..

77. Ray, K.; McCreery, R. L., Anal. Chem. 1997, 69, 4680.

78. Kobayashi, K., Phys. Rev. B 1993, 48, 1757.

79. Giunta, P. L.; Kelty, S. P., J. Chem. Phys. 2001, 114, 1807.

80. Niimi, Y.; Matsui, T.; Kambara, H.; Tagami, K.; Tsukada, M.; Fukuyama, H., Appl. Surf. Sci. 2005, $241,43$.

81. McDermott, M. T.; McCreery, R. L., Langmuir 1994, 10, 4307.

82. Wesner, D.; Krummacher, S.; Carr, R.; Sham, T. K.; Strongin, M.; Eberhardt, W.; Weng, S. L.; Williams, G.; Howells, M.; Kampas, F.; Heald, S.; Smith, F. W., Phys. Rev. B 1983, 28, 2152.

83. Cho, G.; Yen, B. K.; Klug, C. A., J. Appl. Phys. 2008, 104, 013531. 

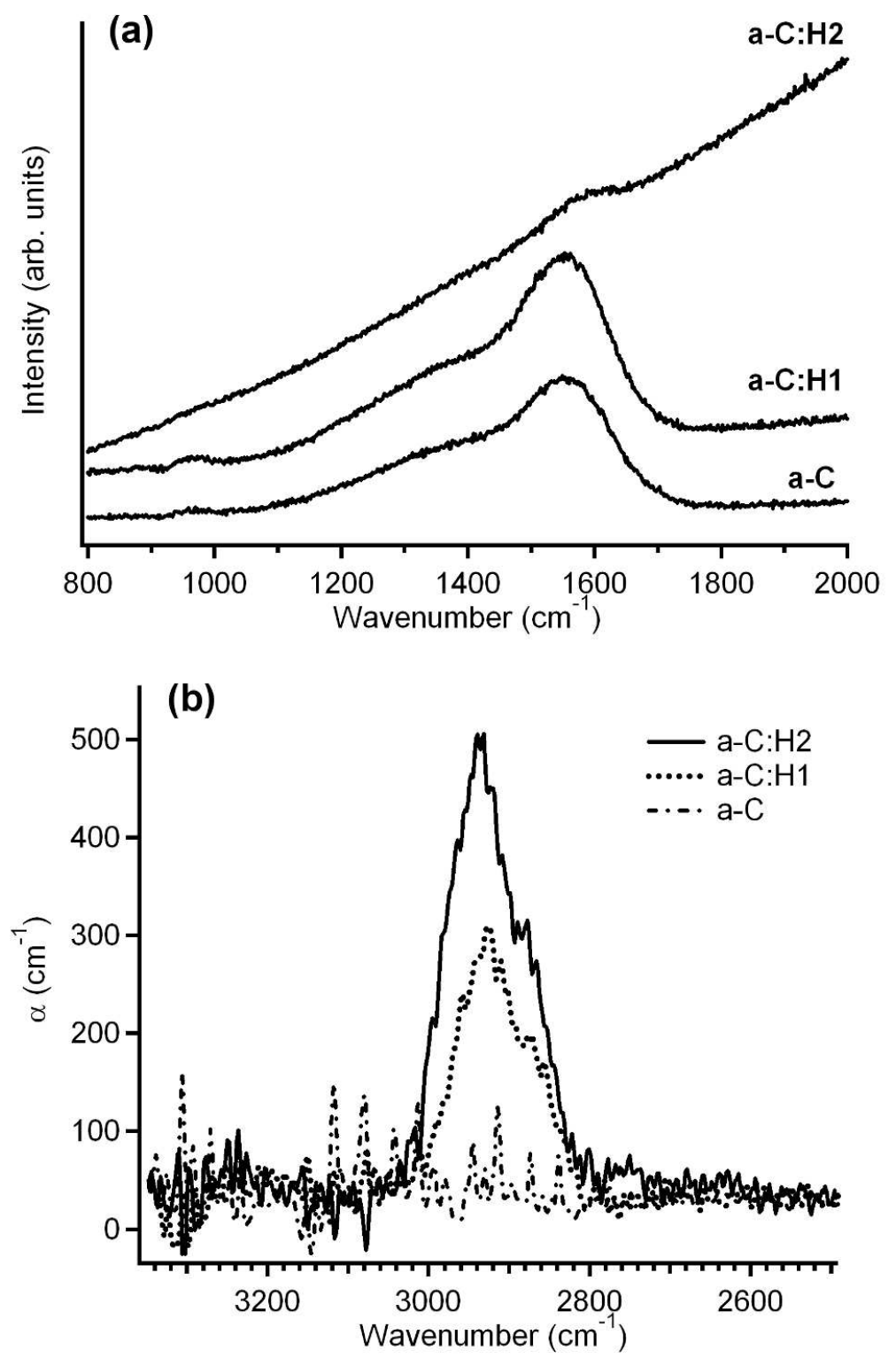

Figure 1. (a) Raman spectra of the three different amorphous carbon films deposited on silicon. Spectra were recorded with a $514 \mathrm{~nm}$ laser line. (b) Absorption coefficient in the $\mathrm{C}-\mathrm{H}$ stretching mode region obtained from infrared spectra of all three carbon films used in our experiments. $82 \times 127 \mathrm{~mm}(300 \times 300$ DPI) 


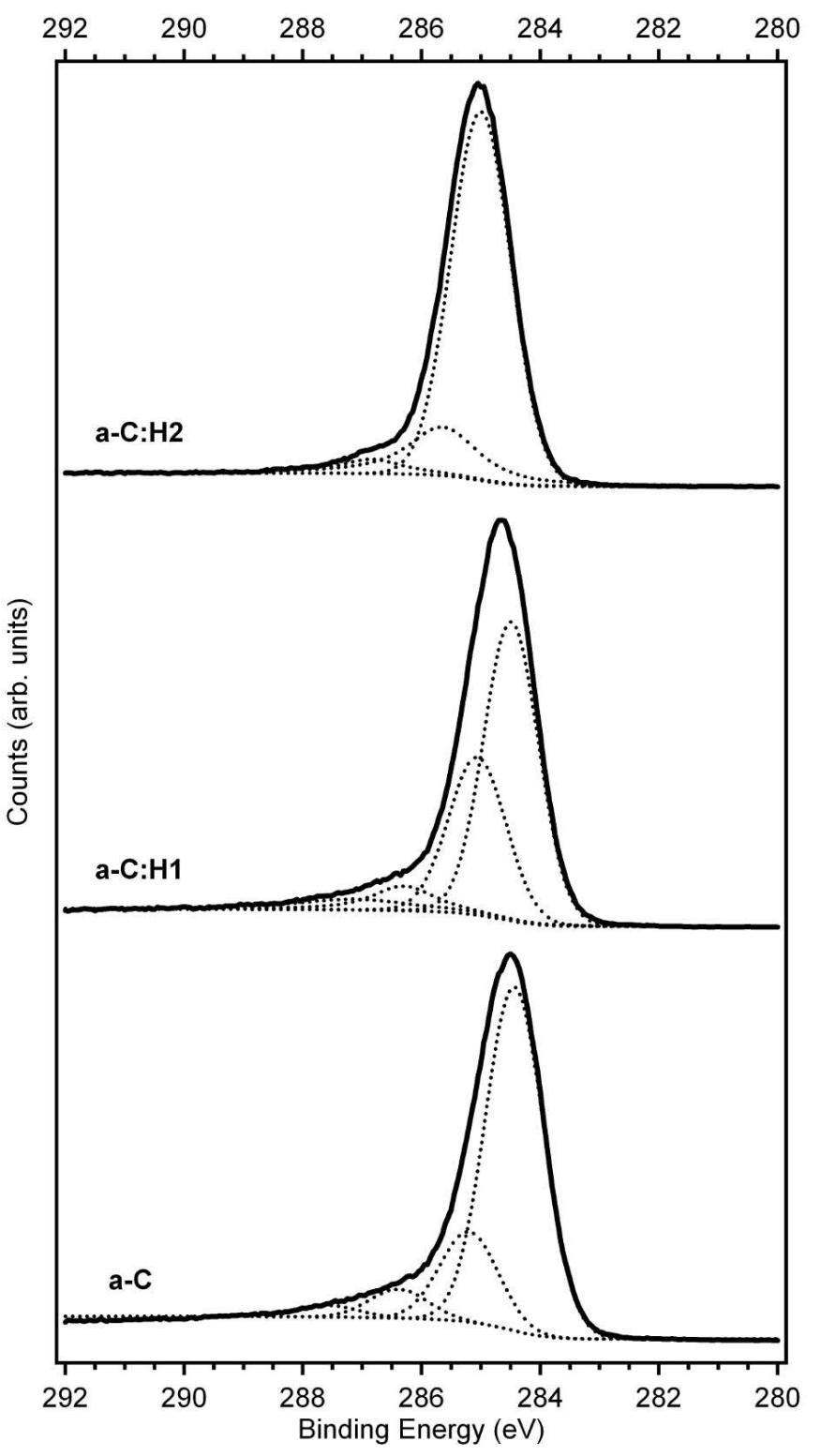

Figure 2. XPS spectra of a-C, a-C:H1 and a-C:H2 films in the $\mathrm{C} 1 \mathrm{~s}$ region; the Shirley background and individual contributions obtained from best fits are shown under each curve. $80 \times 142 \mathrm{~mm}(300 \times 300 \mathrm{DPI})$ 

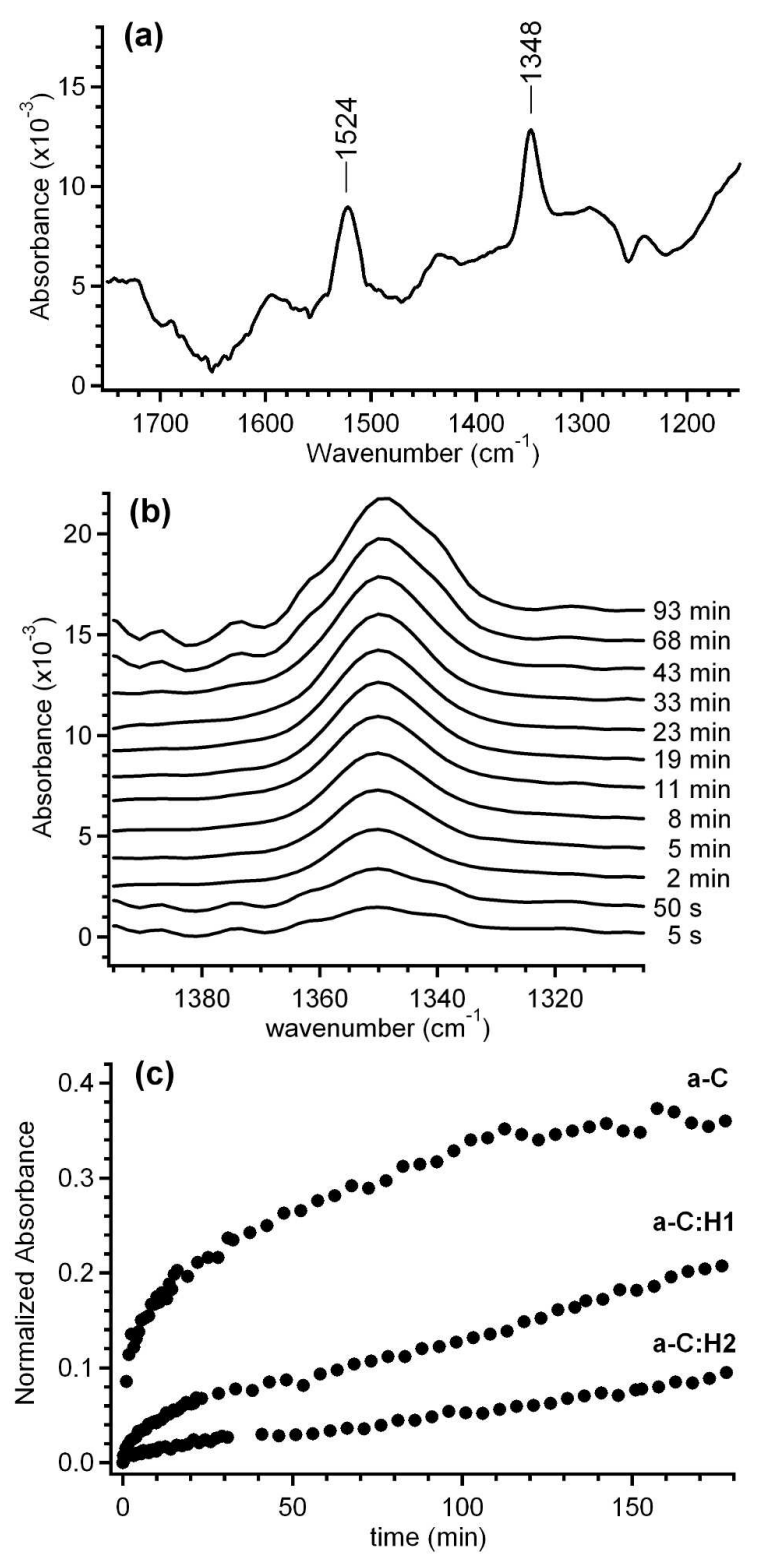

Figure 3. (a) An in situ ATR-FTIR spectrum showing the $\mathrm{N}=\mathrm{O}$ stretching mode region recorded after 120 min deposition on an a-C surface. (b) In situ time evolution of the symmetric $\mathrm{N}=\mathrm{O}$ stretching peak at an a-C surface over 90 min, at selected times after the injection of $1 \times 10^{-4} \mathrm{M}$ pNBD into the ATR-FTIR cell. (c) Curves of normalized net adsorbance vs. deposition time obtained for a-C, a-C:H1 and a-C:H2 films in $1 \times 10^{-4} \mathrm{M}$ pNBD aqueous solutions. $82 \times 170 \mathrm{~mm}(300 \times 300 \mathrm{DPI})$ 


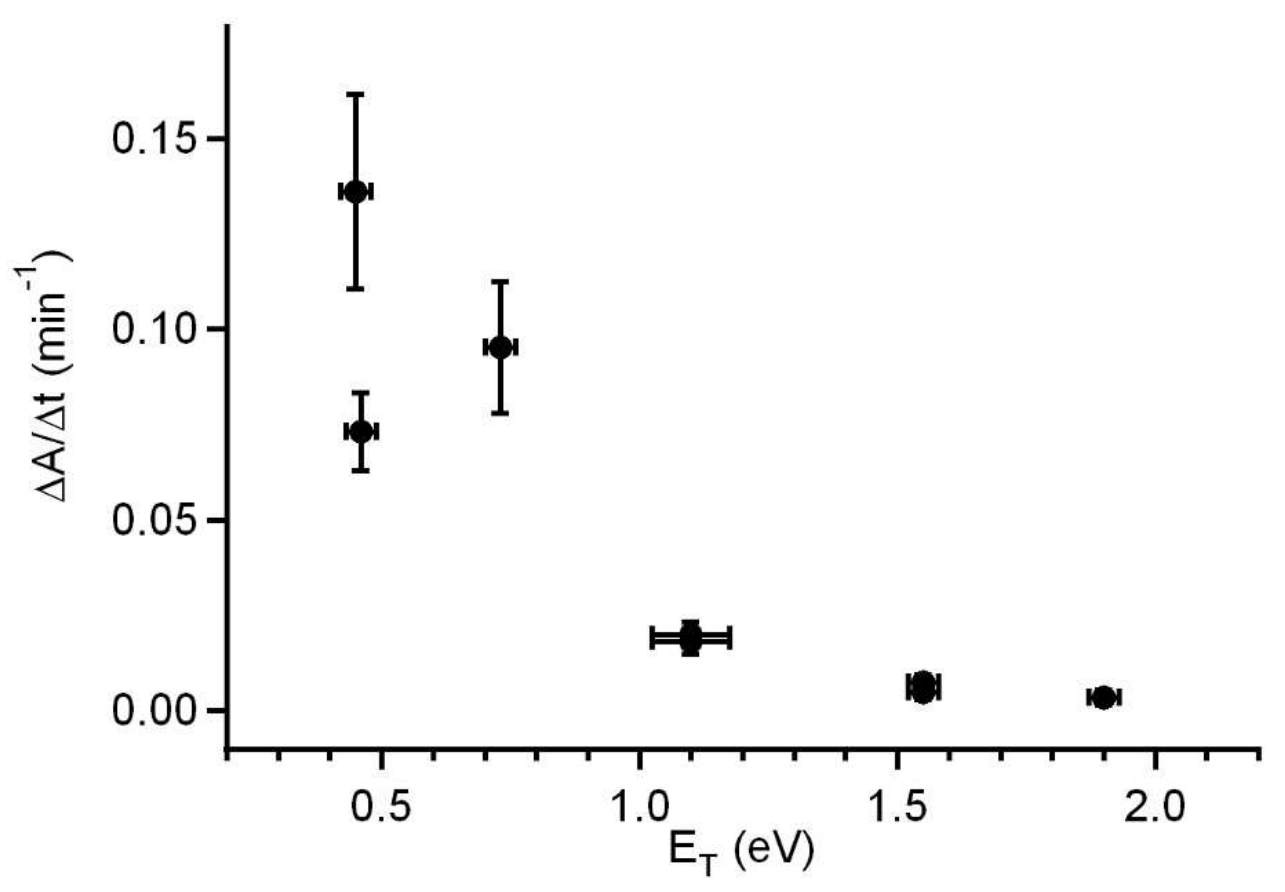

Figure 4. Initial deposition rate obtained from straight line fits in the range 0-1 min. The initial rate is expressed as the ratio $\Delta \mathrm{A} / \Delta \mathrm{t}$ (at $1348 \mathrm{~cm}^{-11}$ ) and reported vs. Tauc bandgap values for each of the samples characterized via in situ ATR-FTIR spectroscopy (error bars represent one standard deviation). Data points in the region $0.4-0.8 \mathrm{eV}, 0.9-1.2 \mathrm{eV}$ and $1.5-2.0 \mathrm{eV}$ are associated to a-C, a$\mathrm{C}: \mathrm{H} 1$ and $\mathrm{a}-\mathrm{C}: \mathrm{H} 2$ carbons, respectively. $80 \times 55 \mathrm{~mm}(300 \times 300 \mathrm{DPI})$ 

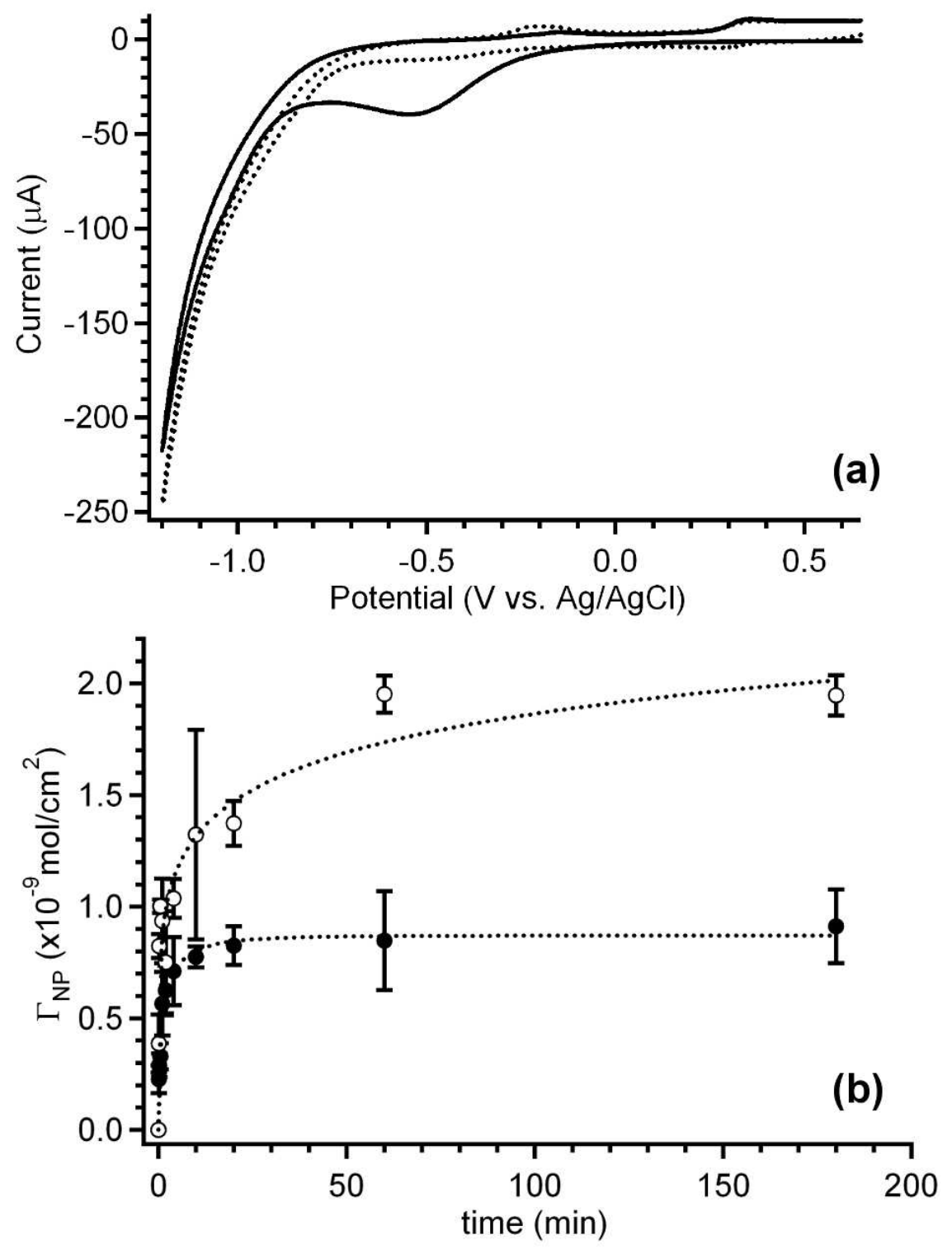

Figure 5. (a) Cyclic voltammogram obtained in $0.1 \mathrm{M} \mathrm{H}_{2} \mathrm{SO}_{4}$ at $0.2 \mathrm{~V} \mathrm{~s}^{-1}$ from a pNBD-grafted a-C electrode; both first $(-)$ and second (---) scans are reported. The carbon electrode was modified via immersion in a $6 \times 10^{-4} \mathrm{M}$ pNBD aqueous solution for $10 \mathrm{~min}$. (b) Surface coverage of nitrophenyl groups, $\Gamma_{\mathrm{NP}}$, on a-C $(\bullet)$ and GC $(0)$ electrodes as a function of deposition time in $6 \times 10^{-4} \mathrm{M}$ pNBD solutions (dotted lines are included to guide the eye). $81 \times 110 \mathrm{~mm}(300 \times 300 \mathrm{DPI})$ 


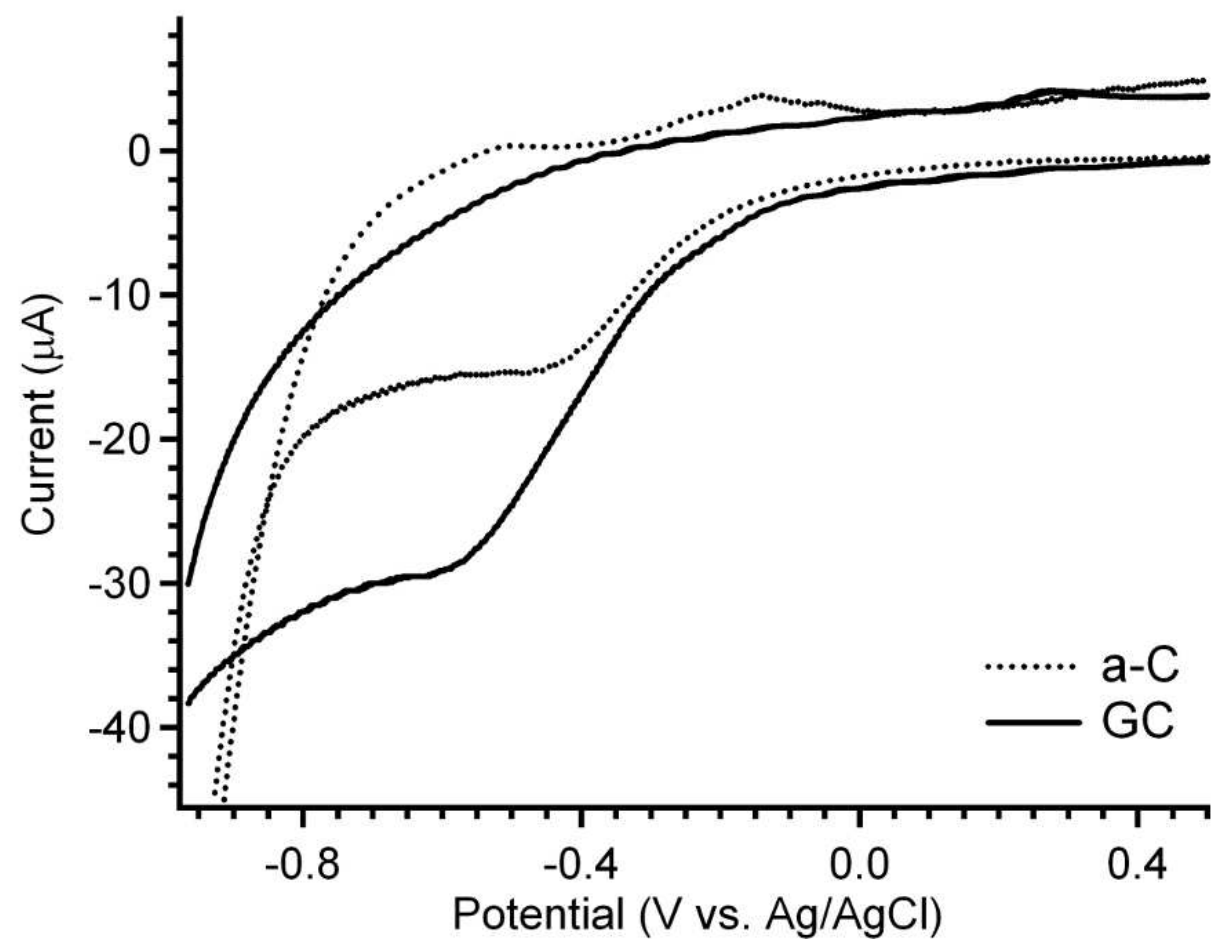

Figure 6. Cyclic voltammetry of a-C and GC electrodes modified via partial intercalation of 4-NBA from acetonitrile solutions, obtained in $0.1 \mathrm{M} \mathrm{H}_{2} \mathrm{SO}_{4}$ at $0.2 \mathrm{~V} \mathrm{~s}^{-1}$. The electroreduction peak of nitrophenyl groups appears at approximately $-0.5 \mathrm{~V}(\mathrm{vs} . \mathrm{Ag} / \mathrm{AgCl})$ as in films modified via pNBD grafting.

$80 \times 59 \mathrm{~mm}(300 \times 300 \mathrm{DPI})$ 


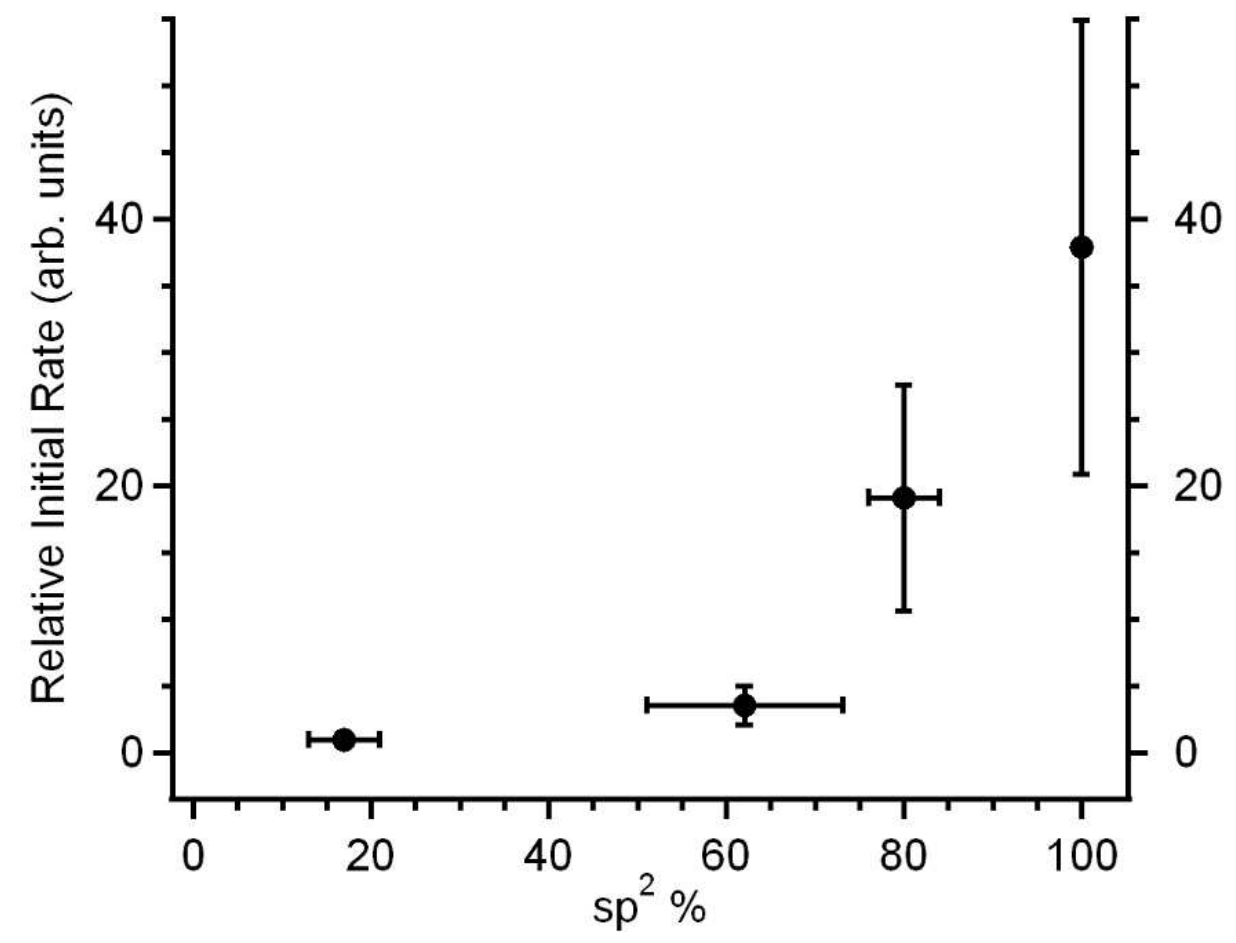

Figure 7. Summary of relative initial rates of pNBD adsorption at amorphous carbon surfaces as a function of $\mathrm{sp}^{2}$ content obtained from combining in situ and ex situ measurements. Rates are plotted relative to that measured at a-C: $\mathrm{H} 2$ samples. $80 \times 59 \mathrm{~mm}(300 \times 300$ DPI $)$ 

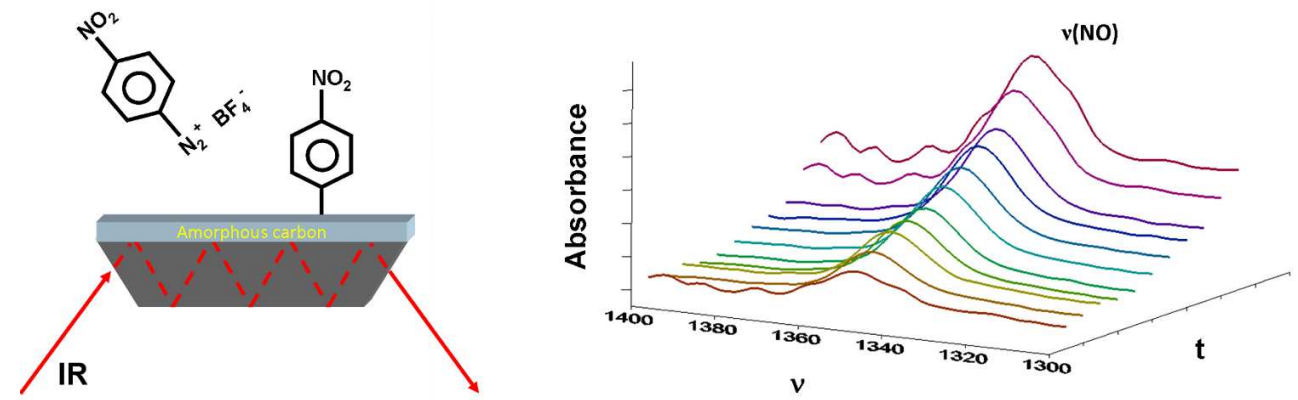

We report for the first time in situ aryldiazonium adsorption measurements at amorphous carbon surfaces of varying composition using ATR-FTIR spectroscopic methods. Adsorption rates were found to increase nonlinearly with an increase in the $\mathrm{sp}^{2}$ content of the films.

$$
129 \times 44 \mathrm{~mm}(300 \times 300 \mathrm{DPI})
$$

